\title{
Atividades metacognitivas como facilitadoras na aprendizagem sobre seres vivos nos anos iniciais
}

Metacognitive activities as facilitators in learning about living beings in the early years

\author{
Sabrina Antunes Ferreira ${ }^{1}$ \\ Geovane Bernardi² \\ Maira dos Santos Silveira ${ }^{3}$ \\ Ariadne de Freitas Leonardi ${ }^{4}$ \\ Andréa Inês Goldschmidt ${ }^{5}$
}

\section{Resumo}

O artigo investiga a inserção de momentos de evocação do pensamento metacognitivo durante a realização de uma sequência didática para o conteúdo seres vivos, desenvolvida com alunos dos anos iniciais em escola pública do município de Palmeira das Missões, RS. O objetivo consistiu em proporcionar que os estudantes recorram a essa forma de pensamento durante as atividades desenvolvidas como meio de qualificar suas aprendizagens. Para tanto, investigaram-se, teoricamente, os elementos metacognitivos e aspectos construtivistas nas vertentes psicológica e epistemológica. Os aspectos construtivistas nortearam a elaboração da Sequência Didática Metacognitiva (SDMc), cuja pesquisa qualitativa foi desenvolvida em distintas fases: sondagem, como forma de revelar a presença de momentos de evocação metacognitiva; discussão inicial com os participantes sobre as concepções iniciais; aplicação da sequência didática; desenvolvimento de instrumento para coleta dos dados e avaliação; e, discussões sobre a viabilidade, para efetivação do modelo proposto. A pesquisa teve como instrumento investigativo a análise oriunda de um questionário inicial e de uma ficha de avaliação, aplicadas aos alunos, além de observações dos pesquisadores. Os resultados permitem inferir que o modelo se mostra pertinente, revelando que a explicitação de momentos de evocação do pensamento metacognitivo representa uma alternativa para tornar as atividades desenvolvidas potencialmente mais significativas na aprendizagem.

Palavras chave: metacognição; sequência didática; ensino de ciências

\section{Abstract}

The article investigates the insertion of moments of evocation of the metacognitive thought during the accomplishment of a didactic sequence for the living beings content, developed

\footnotetext{
1Universidade Federal de Santa Maria | sabrinaantunesferreira@hotmail.com

Universidade Federal de Santa Maria | geovanebernardii@gmail.com

${ }^{3}$ Universidade Federal de Santa Maria | mairasantossilveira@gmail.com

${ }^{4}$ Universidade Federal de Santa Maria | ariadneleonardi@hotmail.com

${ }^{5}$ Universidade Federal de Goiás | andreainesgold@gmail.com
} 
with students of the initial years in public school of the municipality of Palmeira das Missões, RS. The aim was to enable students to use this form of thinking during their activities as a means of qualifying their learning. For that, the metacognitive elements and constructivist aspects in the psychological and epistemological aspects were investigated theoretically. The constructivist aspects guided the elaboration of the Metacognitive Didactic Sequence (McDS), whose qualitative research was developed in different phases: probing, as a way of revealing the presence of moments of metacognitive evocation; initial discussion with participants about initial conceptions; application of didactic sequence; development of an instrument for data collection and evaluation; and, discussions on feasibility, to implement the proposed model. The research had as an investigative instrument the analysis coming from an initial questionnaire and an evaluation form, applied to the students, besides the observations of the researchers. The results allow to infer that the model is relevant, revealing that the explication of moments of evocation of metacognitive thought represents an alternative to make the developed activities potentially more meaningful in learning.

Keywords: metacognition; following teaching; science teaching

\section{Introdução}

As pesquisas sobre o ensino em ciências nos anos iniciais vêm se intensificando nas últimas duas décadas, principalmente em relação às concepções espontâneas de alunos e professores, mudança conceitual, estratégias diversificadas de ensino, alfabetização e letramento científicos, inovações curriculares. Tem sido consensual nessas pesquisas o apontamento relativo à baixa qualidade de ensino e a ineficácia das estratégias metodológicas adotadas, dificuldades dos alunos aprenderem ciências, além dos problemas relacionados à formação de professores para anos iniciais, a qual é pluralista (GOLDSCMHIDT, 2012). Sobre isto, Ducatti-Silva (2005) afirma que o professor termina o curso normal (antes, magistério) e a licenciatura em pedagogia, geralmente sem a formação adequada para ensinar ciências naturais. Assim, o ensino de ciências para os anos iniciais do ensino fundamental é praticado por um professor polivalente, em geral responsável também pelo ensino de outras disciplinas.

Nos anos iniciais a criança defronta-se com o conhecimento científico e sua compreensão dependerá da concepção de ciência e de educação que baliza a prática pedagógica de seus professores. Infelizmente, para muitos docentes, o ensino de ciências naturais é desenvolvido de forma propedêutica.

Campanario e Otero (2000, p. 156) relatam que, no ensino de ciências, a falta de momentos que possibilitem a evocação do pensamento metacognitivo, na forma de estratégia de aprendizagem, tem sido um dos fatores que conspiram cognitivamente contra o trabalho do professor, constituindo-se como obstáculo à aprendizagem significativa por parte dos alunos. Portanto, o ensino de ciências nos anos iniciais deve possibilitar questionamentos, situações problemáticas que levem às crianças a construírem seus primeiros significados importantes do mundo, favorecendo, além da construção de conteúdo conceitual (conceitos, fatos), o desenvolvimento de atitudes científicas, de habilidades e competências, que só podem ser conseguidas por meio de uma orientação adequada e consciente (GOLDSCHMIDT, 2012).

Para Malacarne e Strieder (2009),é importante que a aprendizagem em ciências nos anos iniciais ocorra em meio a um processo de iniciação prazerosa, sob pena de prejudicar 
não apenas aquele momento específico de formação, mas também os resultados do contato posterior com a área em outros níveis de ensino. Assim, as estratégias de ensino devem favorecer a curiosidade inerente da criança, buscar desenvolver seu poder investigativo, além de conservar o espírito lúdico.

É importante destacar que aprender é diferente de compreender, pois provoca mudanças de comportamento, proporciona reflexão sobre o próprio fazer pedagógico e faz do aprender um prazer. As situações de aprendizagem demandam diversas estratégias para que seja viabilizado o aprender. Baseados nesta preocupação surgem as pesquisas sobre a metacognição, que tem despertado o interesse de alguns pesquisadores das ciências cognitivas e de professores preocupados com a prática pedagógica. Desde a década de 1970, pesquisas direcionadas à psicologia cognitiva começaram a investigar de forma mais profícua a preocupação com os aspectos envolvidos na aprendizagem e buscaram oferecer alternativas no intuito de qualificar o processo de ensino.

As contribuições de Piaget e Vygotsky sobre a complexidade dos processos cognitivos impulsionaram o desenvolvimento do conceito de metacognição. Ainda que um termo novo na literatura, já no início do século XX se iniciavam trabalhos com os seus pressupostos. O primeiro autor a apresentar em seus estudos este conceito foi John Flavell na década de 70 (RIBEIRO, 2003). Para Flavell (1970), a metacognição é entendida como a percepção que um indivíduo tem sobre o próprio conhecimento. Etimologicamente, o termo surge como a justaposição de "meta", do grego metá, significando mudança, transcendência e reflexão crítica e "cognição", do latim cognitione, sendo o conjunto dos processos psicológicos mentais, realizados pelo ato pensante, pela percepção, pela classificação e pelo reconhecimento. Toledo (2003) explica que a metacognição é a capacidade do indivíduo desenvolver o pensar sobre seu pensar, expressando como está estruturando o pensamento a respeito de um determinado conhecimento e, se necessário, reelaborá-lo, de modo a refletir sobre esse pensar para conhecer ou encontrar soluções aos desafios propostos.

Rosa (2011) complementa, afirmando que a metacognição é a tomada de consciência do sujeito sobre seus conhecimentos, sobre seu modo de pensar, promovendo a regulação de suas ações. No âmbito educacional, atua como estratégia de aprendizagem, permitindo que os estudantes executem ações a partir da identificação de seus conhecimentos. A sua potencialidade para a aprendizagem reside no fato de que promove nos estudantes um pensar sobre seus conhecimentos, oferecendo-Ihes condições de controlar a execução de suas ações. Os estudantes, ao pensarem ativamente sobre o que estão fazendo, são capazes de exercer um controle sobre seus processos mentais e, assim, obter ganhos cognitivos.

Assim, a teoria da metacognição contribui de forma efetiva para que educadores e educandos desenvolvam suas capacidades motivacionais, criando condições para ampliar o desenvolvimento das competências intrínsecas, potencializando os processos de ensino e aprendizagem. Compreender os determinantes da aprendizagem e da metacognição leva o sujeito à autoaprendizagem, onde a autoconsciência e a busca da superação das limitações devem estar presentes no ato de construir o conhecimento.

Diante do exposto, o artigo investiga a possibilidade de inserir momentos explícitos de evocação do pensamento metacognitivo durante a realização de Sequência Didática Metacognitiva (SDMc) para o conteúdo seres vivos. O objetivo consistiu em proporcionar 
que os estudantes recorram a essa forma de pensamento durante as atividades desenvolvidas como meio de qualificar suas aprendizagens.

\section{A Experiência de Ensino}

Os aspectos construtivistas nortearam a elaboração da Sequência Didática Metacognitiva (SDMc), organizada para o conteúdo seres vivos, desenvolvida com cento e onze (111) alunos dos anos iniciais - segundo ao quinto ano do ensino fundamental - em uma escola pública do município de Palmeira das Missões, RS. As atividades que compõem a SDMc foram desenvolvidas pelo grupo de pesquisadores, autores deste artigo e que se encontram em formação inicial docente em Ciências Biológicas. Teve a participação, como observadores, de seis professores, responsáveis pelas turmas na escola. A amostra constou de duas turmas de $2^{\circ}$ ano, duas turmas de $3^{\circ}$ ano, uma turma de $4^{\circ}$ ano e uma turma de $5^{\circ}$ ano, tendo sido desenvolvida a SDMc em cada uma das turmas participantes, de forma separada e levando-se em consideração o desenvolvimento cognitivo dos estudantes na faixa etária. Trata-se, portanto, de um estudo com crianças na faixa etária entre sete a treze anos.

A SDMc se desenvolveu em cinco fases: (1) sondagem inicial pelo uso de um questionário semi-estruturado sobre as concepções prévias, como forma de revelar a presença de momentos de evocação metacognitiva presente nos anos iniciais; (2) discussão inicial com os participantes sobre as concepções iniciais; (3) sequência didática; (4) desenvolvimento de instrumento para coleta dos dados e avaliação; e, (5) discussões sobre a viabilidade, para efetivação do modelo proposto.

Os alunos foram convidados a participarem da pesquisa, assinando juntamente aos familiares, um termo livre e esclarecido. A fase 1, desenvolveu-se pela aplicação do instrumento de pesquisa, composto por treze perguntas, sendo sete questões fechadas e seis questões abertas. As perguntas fechadas estiveram relacionadas aos dados gerais sobre os sujeitos (turma, idade e gênero) e ideias sobre o reconhecimento dos seres vivos e sobre ciclo de vida. Já as questões abertas estiveram relacionadas às características dos seres vivos; explicações sobre ciclo de vida; características dos seres vivos; diversidade; e necessidades bióticas e/ou abióticas para sobreviverem.

Considerando a forma de coleta de dados, da análise utilizada e o uso do referencial teórico, trata-se de uma pesquisa qualitativa, a partir de um questionário inicial semiestruturado sobre concepções alternativas acerca do conteúdo de ciências, seres vivos. A entrevista semi-estruturada é aquela que parte de certos questionamentos básicos que interessam à pesquisa e oferecem um amplo campo de interrogativas que são fruto de novas hipóteses que vão surgindo à medida que se recebem as respostas do aluno, sendo que o aluno começa a participar na elaboração do conteúdo da pesquisa (NOGUEIRAMARTINS 2004).

A pesquisa empírica consistiu na elaboração e desenvolvimento da SDMc sobre seres vivos e após, a apreciação das concepções iniciais e das atividades por parte dos alunos. Estas avaliações foram desenvolvidastambém dentro de uma abordagem de pesquisa qualitativa, constituindo o corpus de análise, os questionários individuais iniciais e a ficha de avaliação final. Para tanto, recorreu-seà análise de conteúdo, proposta por Bardin (2011). De acordo com a autora, a categorização é uma operação de classificação de elementos constitutivos de um conjunto, por diferenciação e, seguidamente, por reagrupamento 
segundo o gênero (analogia). Ainda para avaliação final, recorreu-se aos registros escritos realizados pelos pesquisadores nos diários de bordo.

Para as fases 2 e 3, foi fundamental a efetivação e análise de dados da primeira fase, de modo que orientassem a proposta de pesquisa, contando com a organização e execução da SDMc. Estas visaram otimizar a internalização de diferentes concepções sobre aprendizagem e ensino, a partir da reflexão e avaliação, por parte dos estudantes, sobre seus próprios processos cognitivos, enquanto abordavam o conteúdo de ciências. Neste intuito, foi discutido com os alunos sobre a sondagem inicial realizada, de modo que as atividades propostas fossem percebidas pelos educandos e estes participassem ativamente do processo de aprendizagem, cientes de suas dúvidas. Proporcionar aos educandos, desenvolver uma visão crítica acerca de suas concepções, desde os anos iniciais, pode contribuir paraestabelecer oportunidades para que os conteúdos não sejam abordados apenas em suas dimensões teóricas e abstratas, permanecendo distantes da vida dos alunos. Tal processo se faz importante, pois promove a interação das novas aprendizagens às concepções prévias, viabilizando aos educandos autorregularem seus processos cognitivos, a partir da reflexão.

A SDMc aplicada na terceira etapa da pesquisa, foi baseada em quatro momentos, totalizando cinco horas de atividades em cada uma das turmas. Os alunos foram organizados em quatro grupos, tendo em cada um deles, um pesquisador como mediador das atividades.

\section{MOMENTO I - Atividade inicial de sensibilização para a temática "seres Vivos"}

Os participantes tiveram os olhos vendados e puderam manipular elementos organizados previamente numa bancada, com diversos exemplares de seres vivos e de elementos não-vivos. Esta atividade teve a intenção em fazer com que as crianças experenciassem as diversas situações pelo tato, tendo como foco central diferenciar o "vivo" do "não-vivo" (Figura 1). Como seres não-vivos, foram utilizadas algumas rochas, um recipiente com água, outro com terra, uma casca de árvore e brinquedos. Como seres vivos, foram utilizadas sementes, minhocas, vaso de plantas, briófitas, um pintinho, frutas, caracóis e lesmas (Figura 2). Buscou-se oportunizar aos participantes a concretização dos conteúdos, uma vez que sem a observação e manipulação, poderiam se tornar abstratos na visão infantil.Somente após a experiência de contato pelo tato, foi retirada a venda dos olhos, para que pudessem olhar o que tinha sobre a bancada. Então, foi estimulada a discussão entre as crianças sobre as semelhanças e as diferenças entre os seres que estavam presentes. Esperava-se que fossem apontadas pelos alunos, as diferenças como sons, movimentos, forma do corpo e a necessidade de alimento, que um grupo apresentava e outro não. Esperava-se ainda que esta etapa contribuísse para que os alunos refletissem criticamente sobre as considerações que haviam sido feitas no questionário inicial e fossem tomando consciência de seus conhecimentos e como poderiam aprender mais, sendo qualificados também a perceberem a interdependência estabelecida entre seres vivos e não-vivos. 


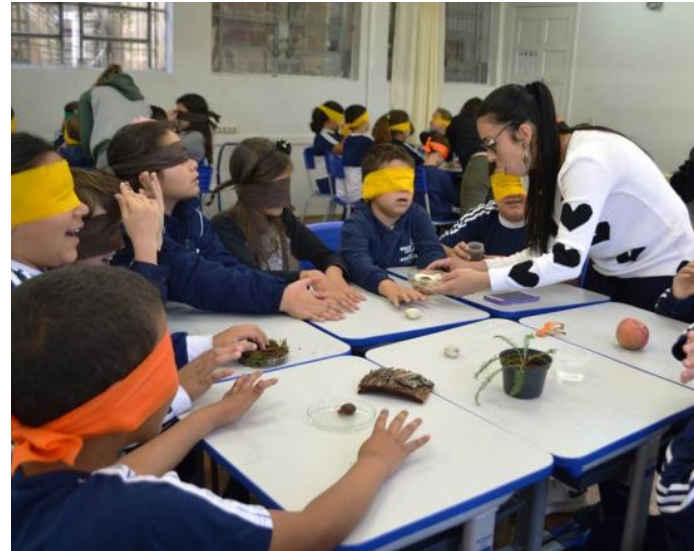

Figura 1. Seres vivos e não-vivos observados pelos alunos através do tato

Fonte: autores

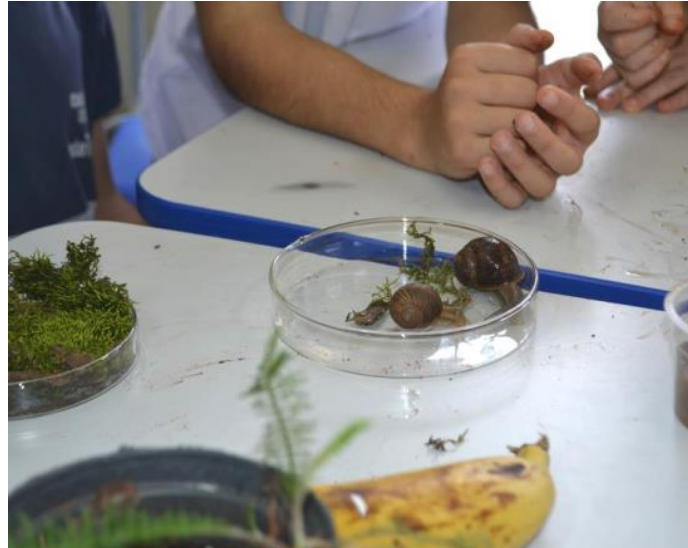

Figura 2. Detalhe da observação dos seres vivos e não-vivos

Fonte: autores

\section{MOMENTO II: Sensibilização para a classificação}

Esta etapa foi complementar à atividade anterior, de modo que os alunos organizassem os elementos em seres vivos e não-vivos, e pudessem iniciar as ideias de classificação. Cada grupo recebeu duas cestas construídas em EVA, contendo vários elementos, entre eles organismos vivos e não-vivos. A atividade consistiu em separá-los nas cestinhas nominadas (Figura 3) e após esta separação, reconhecerem se os seres vivos precisam ou não dos elementos não-vivos para viverem. Tal percepção era importante, uma vez que as concepções iniciais apontavam esta necessidade. Foram trabalhados os mesmos elementos presentes na primeira atividade; porém, foi adicionado um potinho com drosófilas e fermento biológico. Já, como elementos não-vivos foram adicionados fruto seco de timbaúva e tubo de ensaio contendo ar.

Teve-se ainda o intuito de apresentar aos participantes, os organismos vivos menores (fermento-leveduras) e o seu metabolismo. Os alunos foram consultados a respeito do fermento, se este poderia ou não ser um ser vivo. Assim, iniciaram-se uma série de questionamentos sobre como poderiam responder a tal questão. Os alunos foram estimulados a discutir e elaborar possibilidades e listarem características para responder o problema. Estas foram anotadas no quadro. Somente após listarem algumas destas foi desenvolvida uma atividade experimental, fornecendo ao fermento o alimento (açúcar e água) para observarem o que aconteceria (Figura 4). $O$ intuito foi mostrar aos alunos as necessidades biológicas do ser vivo levedura, ao se alimentar, usando um balão de borracha para capturar os gases liberados na fermentação. 


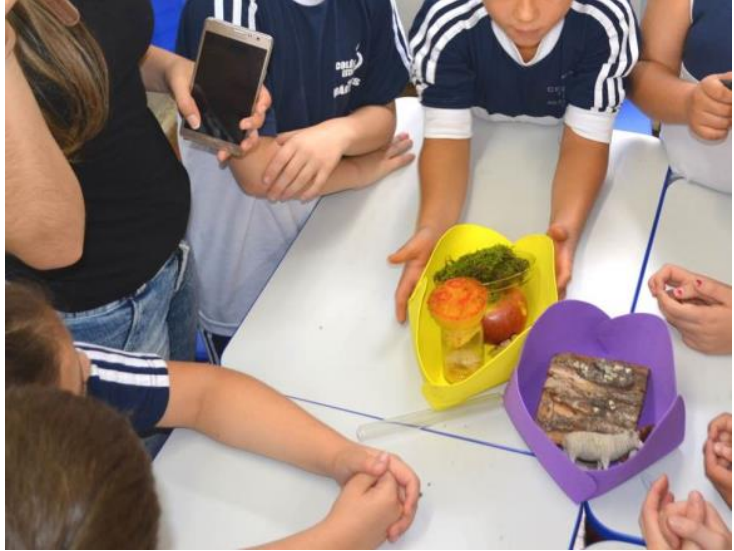

Figura 3. Elementos vivos e não-vivos para classificação inicial

Fonte: autores

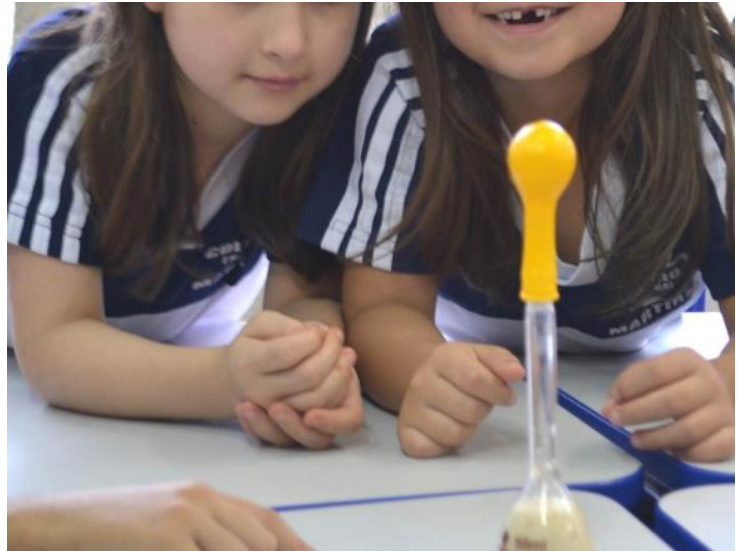

Figura 4. Experimentação com levedura para observação de características dos seres vivos

Fonte: autores

\section{MOMENTO III: Para que serve a classificação?}

Foram apresentadas aos alunos várias imagens (36 fotografias) de organismos vivos, e solicitou-se a eles que imaginassem estes seres vivos na natureza. Após, foram indagados se todos poderiam ser considerados iguais e se possuíam ou não diferenças.

A partir desta observação, iniciaram-se com os participantes, as ideias de classificação biológica. Explicou-se, que considerando todos os grupos de seres vivos é importante para serem melhores estudados, separá-los em grupos, de acordo com suas semelhanças. Para facilitar esta discussão, foi exemplificado que o mesmo acontece quando se encontra diante de uma grande quantidade de coisas diferentes, e busca-se agrupá-las de modo a unir aquelas que possuem características em comum. Para compreenderem melhor, recorreu-se ao cotidiano questionando aos estudantes sobre já terem ido a um supermercado. Indagou-se: Como estão dispostos os produtos no supermercado? Quais são os motivos que levam os proprietários dos supermercados a agruparem os produtos nas prateleiras?

Para contextualizar a classificação biológica, foi explicado que os seres vivos também foram separados em grupos para facilitar o seu estudo. A primeira pessoa que tentou realizar foi um estudioso, Aristóteles, que agrupou todos os seres vivos em dois grupos: os que possuíam sangue e aqueles que não possuíam. Percebeu-se que essa classificação não era a ideal e, portanto, outras foram posteriormente propostas. No final do século 18, Carl Von Linné propôs uma classificação por categorias, baseada nas semelhanças anatômicas. Primeiramente ele considerou que o grupo básico da classificação era uma espécie. Para ele, uma espécie seria um grupo de indivíduos com características não observadas em nenhum outro grupo. Assim, as espécies que não apresentavam alguma semelhança eram agrupadas em grupos distintos. Após, foram questionados sobre que grupos os participantes conheciam. Teve-se o intuito que, ao término dessa atividade, os alunos reconhecessem critérios de seleção para classificar os organismos vivos. Como atividade, cada grupo organizou as fichas de imagens dos seres vivos em um sistema de classificação, de acordo com os critérios que desejassem. Esta organização foi construída sobre uma cartolina e as imagens foram fixadas com fita adesiva, para posterior apresentação à turma. O propósito da atividade era perceberem que pode haver formas distintas de classificação, levando-se em consideração diversas possibilidades. 


\section{MOMENTO IV: Aprendizagem}

Para finalizar as atividades, organizou-se uma roda de conversa, no intuito de sistematizar o conhecimento sobre o que foi aprendido e enriquecido a partir das concepções inicias dos educandos. Neste momento, os alunos tiveram a oportunidade de reconhecer o que sabiam, o que aprenderam e como este conhecimento foi construído por eles. Por fim, os alunos receberam uma ficha avaliativa a ser respondida em casa, sobre as percepções do assunto e as preferênciasdas estratégias utilizadas. Esta ficha foi recolhida e analisada juntamente com as anotações dos pesquisadores em seus diários de bordo.

\section{Resultados e discussão}

A análise global das informações permitiu realizar algumas considerações acerca de como estes alunos compreendem os seres vivos e suas características. Do total de participantes, foi constatado que 54,55\% eram meninos e 45,45\% meninas, com faixa etária de 7 a 13 anos, de acordo com o nível de ensino, coerente à idade para anos iniciais segundo a legislação.

Quadro 1. Percentual de reconhecimento dos seres vivos e características dos microrganismos para alunos de anos iniciais do ensino fundamental de uma escola pública do interior do estado do RS.

\begin{tabular}{|c|c|c|c|c|c|}
\hline Questão & Categorias & $\%$ & Questão & Categorias & $\%$ \\
\hline \multirow{2}{*}{$\begin{array}{c}\text { 1.Ser vivo e ser } \\
\text { não-vivo são } \\
\text { iguais? }\end{array}$} & Sim & 19,32 & \multirow{2}{*}{$\begin{array}{c}\text { 3.Você conhece } \\
\text { seres vivos que } \\
\text { não podemos } \\
\text { ver? }\end{array}$} & Sim & 55,68 \\
\hline & Não & 80,68 & & Não & 44,32 \\
\hline \multirow{12}{*}{$\begin{array}{l}\text { 2. Qual(is) } \\
\text { é(são) sere(s) } \\
\text { vivo(s)? }\end{array}$} & Cachorro & 94,32 & \multirow[t]{12}{*}{ 4.Quais são eles? } & Não responderam & 36,52 \\
\hline & Ser humano & 94,32 & & Insetos & 25,22 \\
\hline & Flor & 77,27 & & Bactérias & 16,52 \\
\hline & Coração & 60,23 & & Vírus & 8,70 \\
\hline & Planta & 60,23 & & Germes/micróbios & 4,34 \\
\hline & Bananeira & 57,95 & & Ácaros & 3,48 \\
\hline & Vírus da gripe & 36,36 & & Microrganismos & 0,87 \\
\hline & Terra & 29,55 & & $\begin{array}{c}\text { Animais bebês e plantas } \\
\text { pequenas }\end{array}$ & 0,87 \\
\hline & Banana & 11,36 & & Fungos & 0,87 \\
\hline & Água & 3,41 & & Pólen & 0,87 \\
\hline & Vento & 2,27 & & Muito pequenos & 0,87 \\
\hline & Pedra & 1,14 & & Seres não vivos & 0,87 \\
\hline \multirow{7}{*}{$\begin{array}{l}5.0 \text { que sabe } \\
\text { sobre os seres } \\
\text { vivos que não } \\
\text { podemos ver? }\end{array}$} & \multicolumn{4}{|c|}{ Não responderam } & 45,91 \\
\hline & \multicolumn{4}{|c|}{ Causam doenças } & 29,59 \\
\hline & \multicolumn{4}{|c|}{ Microscópicos } & 16,33 \\
\hline & \multicolumn{4}{|c|}{ Possuem as características de insetos } & 3,06 \\
\hline & \multicolumn{4}{|c|}{ Possuem benefícios } & 3,06 \\
\hline & \multicolumn{4}{|c|}{ Modo de vida diferente } & 1,02 \\
\hline & \multicolumn{4}{|c|}{ Vivem em qualquer lugar } & 1,02 \\
\hline
\end{tabular}


Os resultados foram calculados pelas médias das respostas dadas do segundo ao quinto ano, pois os participantes não demonstraram conhecimento escolar ampliado nos diferentes níveis de ensino, para as questões relacionadas à temática. Desta forma, optou-se em elaborar a SDMc para todas as turmas em que se aplicou o questionário inicial.

O Quadro 1 apresenta os resultados quantificáveis em percentuais para cinco questões aplicadas aos alunos, sendo que as questões 1, 2 e 3 eram perguntas fechadas e as demais, permitiam aos alunos respostas elaboradas por eles. Isto é importante destacar, pois na questão dois, os alunos tinham liberdade em marcar mais de uma alternativa, o que permite que o resultado para esta questão tenha mais respostas, ultrapassando o somatório de $100 \%$.

Em relação às concepções iniciais sobre como os alunos reconhecem os seres vivos, embora 80,68\% dos alunos identificaram que os seres vivos e não-vivos não são sinônimos, percebeu-se que os participantes apresentaram várias dificuldades quanto ao reconhecimento destes, o que pode gerar futuros obstáculos de aprendizagem. As crianças apresentaram confusão em classificarem coração, planta, bananeira, banana e vírus da gripe. Estes resultados mostram que ainda não conseguem diferenciar partes estruturais de seres vivos, uma vez que apenas são trabalhados exemplares e algumas características vitais. Observou-se ainda um percentual considerável de alunos que reconhecem a terra como sendo um ser vivo $(29,55 \%)$.

Freitas (1989) em seus estudos afirmou que as crianças menores ( $3^{\circ}$ ano) têm um conhecimento pouco aprofundado acerca de seres vivos porque estudaram tais conteúdos a partir de exemplos selecionados com base num quadro restrito de critérios. Segundo o autor, o conceito de ser vivo, geralmente, inicia no $3^{\circ}$ ano, mas ainda voltado para as características vitais (nascer, crescer, respirar, alimentar-se, reproduzir e morrer). Somente no segundo ciclo do ensino fundamental, que se inicia a relativização do conceito de ser vivo o qual depende de propriedades específicas como a organização celular que está relacionada aos critérios da teoria celular, como atributo característico dos seres vivos. Assim, esta falta de maior amplitude dos conceitos poderá dificultar a compreensão da funcionalidade dos seres vivos mais tarde. Moura (2000) corrobora, evidenciando em seus estudos com alunos de anos inicias que estes no primeiro ano do ensino fundamental, apontam como complexo classificar os elementos como seres vivos ou não-vivos, além de possuírem um conceito não científico de ser vivo.

Os vírus não foram reconhecidos como organismos vivos (63,64\%), e quando os participantes foram questionados sobre conhecerem formas microscópicas vivas, um percentual significativo também afirmou não conhecer (44,32\%). Já, no momento de citarem quais microrganismos conheciam, observou-se a dificuldade em exemplificar, sendo mais citados insetos $(25,22 \%)$ e bactérias (16,52\%). Podemos inferir que há uma relação entre o fato de classificarem insetos como microrganismos por estabelecerem uma relação entre insetos e riscos ou danos ao homem. Costa Neto e Carvalho (2000) apresentam que o senso comum julga os insetos como sendo organismos nojentos, perigosos, repugnantes e inúteis para a sociedade. Esta mesma associação foi feita pelos alunos, quando questionados sobre as características dos microrganismos. Ao comparar estes resultados com as respostas apontadas pelos alunos sobre as concepções que apresentavam a respeito dos microrganismos, 45,91\% não souberam responder nada sobre o grupo, enquanto 29,59\% afirmaram que estes são causadores de doenças e 16,33\% os definiram como microscópicos. Benefícios praticamente não foram reconhecidos pelos participantes 
(3,06\%). Tais resultados mostram fragilidades quanto a estes conhecimentos científicos, que se não adequadamente trabalhados, podem influenciar no processo de aprendizagem, além da não valorização a todas as formas de vida.

Os resultados encontrados estão em consonância com o trabalho de Byrne e Sharp (2006), com crianças nesta mesma faixa etária, em escolas da Inglaterra, quando mostraram que todos os alunos envolvidos na pesquisa concebem os microrganismos como seres que não trazem benefícios para a humanidade e que a maioria das atividades de ensino não traz êxito para a mudança de pensamento dos alunos. Os microrganismos são concebidos apenas como causadores de doenças. Byrne (2003) aponta que o uso de microrganismos para a produção de alimentos parece ser pobremente entendido e embora os microrganismos habitem diferentes espaços, muitos alunos, associa-os às doenças e lugares não higiênicos. Essa associação aumenta com a idade.

O Quadro 2 apresenta os resultados quantificáveis em percentuais para três questões aplicadas aos alunos, sendo que destas, apenas a questão 6, trata-se de pergunta fechada.

Quadro 2 - Percentual sobre ciclo de vida e as necessidades dos seres vivos para alunos de anos iniciais do ensino fundamental de uma escola pública do interior do estado do RS.

\begin{tabular}{|c|c|c|c|c|c|c|}
\hline Questão & Categorias & $\%$ & Questão & Categoria & Subcategorias & $\%$ \\
\hline \multirow{2}{*}{$\begin{array}{l}\text { 6. Você sabe o } \\
\text { que é ciclo de } \\
\text { vida? }\end{array}$} & Sim & 63,64 & \multirow{12}{*}{$\begin{array}{l}\text { 8. O que os } \\
\text { seres vivos } \\
\text { precisam } \\
\text { para viver? }\end{array}$} & \multirow{8}{*}{$\begin{array}{l}\text { Fatores } \\
\text { bióticos e } \\
\text { abióticos }\end{array}$} & Alimentação & 31,78 \\
\hline & Não & 36,36 & & & Água & 32,63 \\
\hline \multirow{10}{*}{$\begin{array}{l}\text { 7. Explicações } \\
\text { para ciclo de vida }\end{array}$} & Não respondeu & 26,67 & & & Oxigênio & 15,69 \\
\hline & $\begin{array}{c}\text { Processo (nasce, } \\
\text { cresce, reproduz } \\
\text { e/ou morre) }\end{array}$ & 51,11 & & & Sol & 7,20 \\
\hline & $\begin{array}{c}\text { Necessidades } \\
\text { básicas }\end{array}$ & 6,68 & & & Solo & 2,97 \\
\hline & $\begin{array}{c}\text { Vida de animais } \\
\text { e humanos }\end{array}$ & 4,44 & & & Abrigo & 2,12 \\
\hline & Cadeia alimentar & 3,33 & & & Chuva & 0,42 \\
\hline & $\begin{array}{c}\text { Proteção dos } \\
\text { seres vivos }\end{array}$ & 3,33 & & & Plantas & 0,85 \\
\hline & \multirow[t]{2}{*}{ Exemplificou } & \multirow[t]{2}{*}{2,22} & & \multirow[t]{2}{*}{ Processos } & Reproduzir & 0,42 \\
\hline & & & & & Dormir & 0,42 \\
\hline & $\begin{array}{c}\text { Difícil, cansativo } \\
\text { e agressivo }\end{array}$ & 1,11 & & $\begin{array}{l}\text { Visão } \\
\text { cósmica }\end{array}$ & $\begin{array}{c}\text { Do mundo } \\
\text { inteiro, de tudo }\end{array}$ & 0,42 \\
\hline & $\begin{array}{c}\text { Deus criou os } \\
\text { humanos }\end{array}$ & 1,11 & & Outros & $\begin{array}{c}\text { Órgãos, } \\
\text { sentimentos, } \\
\text { roupas }\end{array}$ & 5,08 \\
\hline
\end{tabular}

Apesar dos alunos afirmarem saber o que é ciclo de vida (63,64\%); apenas 51,11\% descreveram o mesmo, e ainda de forma bastante reducionista, baseado no processo metabólico simplista "nascer, crescer, reproduzir e/ou morrer", ainda presente em livros didáticos de ciências nos anos iniciais. Lawson (1982) define este tipo de conhecimento como conhecimento declarativo dogmático, uma vez que não é baseado em experiência, mas representa simplesmente a repetição de demonstrações feita por figuras de autoridade do professor. Isso não está de acordo com os objetivos do ensino das ciências modernas e revela o quanto os professores ainda trabalham apenas com transmissão de informações, 
sendo que as estratégias de ensino são importantes para a aquisição, retenção e reprodução da informação e determinam os processos cognitivos (ANDRETTA et al., 2010).

O conceito de ser vivo e de ciclo de vida abrangem uma série de concepções que deles são derivados (habitat, tamanho, funcionalidade, comportamento). Assim, para se desenvolver estes conceitos complexos, entender a natureza das concepções dos estudantes, torna-se primordial, e deve-se seguir uma hierarquia de considerações que envolvem especificidades de um conhecimento integrado sobre os sistemas orgânicos dos seres vivos. Percebe-se a necessidade de atividades experimentais práticas referentes ao ciclo de vida como, por exemplo, metamorfose de insetos e girinos; germinação de sementes e desenvolvimento de plantas como o feijão, pois as ideias abstratas são de difícil compreensão, sendo o processo de observação, importante para o ensino de ciências.

Os resultados da questão sobre o que os seres animados precisam para viver indicaram uma visão limitada dos respondentes, sendo quase que exclusivamente reconhecido as necessidades associadas à alimentação (alimentos e água) e a respiração (oxigênio). Isto sinaliza inclusive a dominância de conceitos de necessidades animais, uma vez que foram manifestadas as ideias sobre a natureza heterotrófica, já que o sol quase não foi citado, apenas em 7,20\% dos casos. O mesmo ocorreu para o apontamento das necessidades respiratórias animais, aparecendo apenas a importância do oxigênio e não dos outros gases. O solo igualmente foi pouco representado, sendo fundamental a todos os processos de crescimento das plantas.

Kwen (2005) realizou uma investigação em escolas de Singapura, envolvendo os níveis de ensino equivalentes ao ensino fundamental I ( $2^{\circ}$ ao $5^{\circ}$ ano), vigente no Brasil. Os resultados da pesquisa mostraram muitos equívocos dos estudantes em relação às plantas, animais e funções vitais dos seres vivos (respiração, circulação e trocas gasosas com o meio ambiente). Apesar de serem introduzidos os conteúdos como as necessidades básicas da água, alimento e ar para todos os elementos vivos; os alunos aprendem as diversas partes das plantas e suas funções básicas, mas ainda não conseguem elaborar uma compreensão da relação entre as trocas gasosas externas e a respiração interna. As evidências são fortes de que os professores precisam avançar no conhecimento da visão sistêmica na escola primária frente à organização dos conteúdos nos referidos anos escolares, e no conhecimento dos alunos sobre as funções do organismo humano.

Quadro 3 - Percentual sobre diferenças existentes entre os animais e as plantas para alunos de anos iniciais do ensino fundamental de uma escola pública do interior do estado do RS.

\begin{tabular}{|c|c|c|c|c|c|}
\hline Categorias & Subcategorias & $\%$ & Categorias & Subcategorias & $\%$ \\
\hline \multirow[t]{6}{*}{ Processos } & Locomoção dos animais & 44,45 & \multirow[t]{6}{*}{ Características } & Tamanho distinto & 5,05 \\
\hline & Alimentação/Fotossíntese & 15,15 & & Coloração distinta & 2,02 \\
\hline & Nascimento distinto & 4,04 & & $\begin{array}{l}\text { Animais possuem } \\
\text { pelos }\end{array}$ & 2,02 \\
\hline & Respiração distinta & 3,03 & & Remédios vegetais & 2,02 \\
\hline & Reprodução distinta & 1,01 & & $\begin{array}{c}\text { Presença de } \\
\text { sementes em plantas }\end{array}$ & 1,01 \\
\hline & Produtores e Consumidores & 1,01 & & $\begin{array}{c}\text { Animal é de carne e } \\
\text { osso }\end{array}$ & 1,01 \\
\hline \multirow[t]{2}{*}{ Comportamento } & Comunicação entre animais & 4,04 & \multicolumn{2}{|c|}{ Planta não é ser vivo } & 2,02 \\
\hline & Pensamento nos animais & 1,01 & \multirow{2}{*}{\multicolumn{2}{|c|}{ São seres vivos diferentes }} & 6,06 \\
\hline \multicolumn{3}{|c|}{ Não responderam } & & & 5,05 \\
\hline
\end{tabular}


O Quadro 3 apresenta os resultados quantificáveis em percentuais sobre as diferenças existentes entre animais e plantas. Os participantes apontaram distinções relacionadas aos processos metabólicos, ao comportamento, características gerais e classificação como seres vivos ou não.

Ao se observar os resultados verificou-se que os alunos usam principalmente os processos vitais para diferenciarem os organismos vivos animais de vegetais. As expressões citadas por eles com conceituação para seres vivos "nascem, crescem, reproduzem e morrem", assumem representatividade também para esta questão; no entanto, percebeu-se que a maior valorização está associada à "locomoção", totalizando 44,44\%. Em conversa com os alunos, percebeu-se não existir mudança conceitual cognitiva ao longo dos níveis de ensino; ou seja, independente das turmas questionadas sobre tal situação, a resposta permaneceu estável.

Piaget (1976) afirma que o desenvolvimento do conceito de vida ocorre sequencialmente, obedecendo quatro estágios. No primeiro estágio, entre quatro e seis anos de idade, a criança considera vivo qualquer objeto que tenha alguma atividade, utilidade ou função. No segundo estágio, entre os seis e oito anos, a criança atribui vida a tudo que se move. No terceiro estágio, entre oito e dez anos, a criança passa a considerar ser vivo tudo que tem movimento próprio e espontâneo. Finalmente, no quarto e último estágio, que ocorre após os onze anos, a criança atribui vida somente às plantas e animais. Desta forma, a incidência do movimento e da força vital reconhecida ao "ser vivo" indica uma indiferenciação conceitual entre ser vivo e animado. A atividade ou movimento, presente neste argumento, evidencia-se central na trajetória desenvolvimental piagetiana do conceito de vida e esteve presente nas turmas investigadas.

Ainda foram reconhecidos pelos investigados, de forma reduzida, os caracteres externos (tamanho, coloração, pelos), e/ou internos (ossos e substâncias medicinais) para diferenciar um animal de uma planta. Segundo Vygotsky (1991), as crianças, em geral, usam os conhecimentos imediatos para diferenciar as plantas dos animais, pois são capazes de perceber primeiramente as diferenças entre os objetos e /ou fenômenos para depois perceber as semelhanças. Por isso a importância do professor ao desenvolver os conteúdos de ciências, iniciar pela observação, atentando inicialmente para as semelhanças entre os objetos, para após buscar as diferenças.

\section{Contribuições da sequência didática metacognitiva para a temática Seres vivos}

As atividades desenvolvidas foram diversificadas e buscaram confrontar as concepções dos alunos oriundas do pré-teste, com o conteúdo que estava sendo desenvolvido, oportunizando um espaço para exposição deconceitos e dificuldades, sempre valorizando as respostas e a participação dos alunos, envolvendo-os no processo de aprendizagem. Tal estratégia corroborou com a ideia de que um "bom aluno é o aluno envolvido, pois o envolvimento da criança na atividade e nos projetos é considerado indispensável para que se dê significado às experiências, sendo essencial para que construa conhecimentos e aprenda a aprender" (OLIVEIRA-FORMOSINHO, 2007, p.24). Desta forma, cada pesquisador-mediador, sondava nos grupos de estudantes os critérios que orientavam as decisões tomadas e os motivava a explorar os argumentos que os levaria, em cada situação concreta, ao conceito de ser vivo. 
Quadro 4 - Percentual sobre as preferências dos estudantes e/ou sobre o que aprenderam após a realização da SDMc para alunos de anos iniciais do ensino fundamental de uma escola pública do interior do estado do RS.

\begin{tabular}{|c|c|c|}
\hline Categorias & Subcategorias & $\%$ \\
\hline \multirow{9}{*}{$\begin{array}{c}\text { Reconhecimento } \\
\text { das estratégias } \\
\text { usadas }\end{array}$} & Citou experimento & 20,30 \\
\hline & Explicou experimento & 19,55 \\
\hline & Relato das coisas que foram separadas na cesta & 12,03 \\
\hline & Explicação das coisas que foram separadas na cesta & 5,26 \\
\hline & Citou as cartas de classificação ou o cartaz para formar grupos & 14,29 \\
\hline & Explicou a classificação & 9,77 \\
\hline & Classificou em animais vertebrados e invertebrados & 9,77 \\
\hline & Reconhece a importância em separar em vivo e não-vivo & 8,27 \\
\hline & Possibilidade em tocar de olhos vendados em coisas vivas e não-vivas & 0,76 \\
\hline & Subtotal & 31,74 \\
\hline \multirow{9}{*}{$\begin{array}{l}\text { Características } \\
\text { gerais }\end{array}$} & Curiosidades sobre os animais & 33,67 \\
\hline & $\begin{array}{c}\text { Características dos seres vivos - andam, respiram, vivem, comem, } \\
\text { podem se reproduzir, morrem }\end{array}$ & 27,55 \\
\hline & Irritabilidade - reação & 15,31 \\
\hline & Exemplos de seres vivos e não-vivos & 6,12 \\
\hline & Hábitos dos animais & 6,12 \\
\hline & Ambientes que os animais vivem & 5,10 \\
\hline & Necessidades para viver (água, alimento, oxigênio, energia) & 3,06 \\
\hline & Plantas se alimentam pela raiz e a água é fonte de vitamina para ela & 2,04 \\
\hline & Nomes de bichos que não conhecia & 1,03 \\
\hline & Subtotal & 23,39 \\
\hline \multirow{3}{*}{$\begin{array}{c}\text { Presença de } \\
\text { animais - } \\
\text { *Somente um } \\
\text { aluno não gostou }\end{array}$} & Possibilidade de tocar em animais como a minhoca, pintinho e caracol & 54,90 \\
\hline & Citou a presença dos animais & 27,45 \\
\hline & Nojo de pegar animais & 17,65 \\
\hline \multirow{8}{*}{$\begin{array}{c}\text { Reconhecimento } \\
\text { dos exemplares } \\
\text { como vivos e } \\
\text { não-vivos }\end{array}$} & Subtotal & 12,17 \\
\hline & Fermento é um ser vivo & 46,81 \\
\hline & Musgo é um ser vivo e vive em lugares úmidos & 19,15 \\
\hline & A água/ ar/ pedra/ terra, não é ser vivo & 12,78 \\
\hline & Semente é viva & 10,64 \\
\hline & Casca do tronco de árvore não é viva & 6,38 \\
\hline & Orelha-de-macaco sem semente não é vivo & 2,12 \\
\hline & Fruta é um ser vivo continua respirando & 2,12 \\
\hline \multicolumn{2}{|r|}{ Subtotal } & 11,22 \\
\hline \multirow{6}{*}{$\begin{array}{l}\text { Preservação e } \\
\text { cuidados }\end{array}$} & Importância dos seres vivos e do meio ambiente - preservar e cuidar & 29,41 \\
\hline & Seres não-vivos fornecem nutrientes para seres vivos & 26,47 \\
\hline & Não machucar os animais ou matar para não ocorrer a extinção & 20,59 \\
\hline & Seres vivos e não-vivos precisam uns dos outros & 17,65 \\
\hline & Importância das plantas não só para nosso consumo & 2,94 \\
\hline & Coitados dos animais de circo, de laboratório, tirados de suas casas & 2,94 \\
\hline & Subtotal & 8,11 \\
\hline
\end{tabular}

Era fundamental, que os alunos discutissem a partir de suas concepções prévias, e experienciassem o conteúdo real e não abstrato, possibilitando o desenvolvimento da criticidade sobre as ideias elaboradas. A participação dos alunos foi extremamente intensa e 
todos se envolveram de forma curiosa e entusiástica. Eles aparentaram gostar de desenvolver as tarefas; observar, tocar, estabelecer comparações. Estes resultados foram visivelmente observáveis e também expostos pelos alunos que, ao término, responderam a avaliação final.

No Quadro 4, são apresentadas as categorias, subcategorias e percentuais obtidos a partir da análise das fichas de avaliação preenchidas pelos alunos e as discussões sobre os processos metacognitivos, a partir das anotações em diário de bordo dos professores pesquisadores. Foi possível, a partir das leituras das fichas de avaliação, organizar as respostas dos alunos em cinco categorias elucidadas no quadro abaixo.

A primeira categoria, mais representativa $(31,74 \%)$, se referiu ao uso das estratégias que compuseram a SDMc e mostram que todas as atividades desenvolvidas tiveram boa aceitação e participação por parte das crianças, sendo citados por eles, tanto os experimentos, a classificação dos elementos vivos e não-vivos nas cestas e ainda as atividades de classificação. É importante destacar, que um contingente significativo de participantes, além de citar as estratégias, explicou o desenvolvimento e as conclusões que chegaram a partir da aula. A diversificação de atividades, além de ser um elemento importante para o ensino em ciências é fundamental para o processo de aprendizagem. Basear o ensino de ciências apenas nos textos, além de torná-lo monótono e desinteressante, não revela a dinâmica da vida nos ambientes do entorno dos estudantes. Ficou explícito que a observação é uma ferramenta valiosa para desenvolver o olhar dos estudantes, incitar-Ihes conflito cognitivo, interpretando as novas informações baseando-se nas referências próprias, principalmente levando em consideração o estudo dos seres vivos.

Laburú, Arruda e Nardi (2003), comentam que a utilização de diversas estratégias possui vantagens e restrições e que a diversificação destas implica em um pluralismo didático que não visa substituir um conjunto de regras por outro, mas sim opor-se a um princípio único, aparentemente imutável. Discutem ainda, que o uso de uma metodologia pluralista, não deve se limitar há apenas adotar diversas estratégias de ensino sem um motivo conciso, só para quebrar a rotina em sala de aula. Assim, é fundamental no ensino de ciências esclarecerem a intencionalidade de todos os tipos de atividade.

Os participantes também citaram de forma relevante as características gerais dos organismos vivos (23,39\%). Nesta, teve destaque a subcategoria "curiosidades referentes aos seres vivos", em especial relacionados aos exemplares levados para a sala de aula. Lopes (2005) comenta que a observação, a exploração e a possibilidade de desfrutar do meio natural se constituem em experiências imprescindíveis para o desenvolvimento da consciência ambiental. O contato com pequenos animais, além de sensibilizar as crianças, auxiliando a desenvolver sentimentos de afeto, também pode caracterizar oportunidades de elevar o nível de conscientização sobre o meio ambiente.

Nesta categoria ainda é importante destacar o reconhecimento da característica irritabilidade. Os alunos concluíram que definir os organismos vivos como "nasce, cresce, reproduz e morre", é bastante limitado e ao interagir com os elementos, constataram características comportamentais, tornando-se observável e compreensível o conceito de irritabilidade. Tal conceito se trata de uma nova aquisição de conhecimento, à medida que constaram este comportamento nos exemplares vivos e ampliaram seus conceitos simplistas de ser vivo. Cavalcante, Cavalcante e Lichston (2011) conceituam irritabilidade como a capacidade de os seres vivos reagirem aos estímulos externos ou ambientais. Graças a esta capacidade, os organismos conseguem adaptar-se às mudanças e garantir a sua 
sobrevivência. Ao observarem esse fato, os alunos discutiram e perceberam que os animais, como os caracóis e as minhocas, eram capazes de se esconderem e/ou de mudarem o caminho quando tocados; já os elementos não-vivos, não apresentavam tal característica. Desta forma, concluíram que apenas os seres vivos possuíam irritabilidade, sendo destacado este comportamento por 15,31\% dos alunos.

Ao separarem os elementos nas cestas em seres vivos e não-vivos, discutiram sobre as características de cada elemento. Dos comentários que foram tecendo ao longo do processo de classificação e das justificações que apresentaram nos grupos, emergiu de forma significativa a atribuição de qualidades funcionais, que incluíram "alimentarem-se, mexerem-se e morrerem". Assim, uma das características mais significativas, presente tanto na sondagem inicial realizada como nas discussões dos alunos se referiu à capacidade de movimentação. Eles também observaram e discutiram sobre a existência de seres vivos que não apresentam movimentos consideráveis (como é o caso das plantas) e de seres nãovivos que conferem algum movimento (como a água e o ar), concluindo que esta classificação inicial era de fato, muito simplista. A ideia prévia sobre emissão de sons, também foi refletida à medida que observaram que há seres vivos que não emitem sons ou que estes podem não ser captados pelo sentido humano (minhocas e as plantas). Inclusive perceberam que pode haver sons emitidos naturalmente e sons externos produzidos, como quando observaram baterem uma rocha em outra. Assim, oportunizou-se às crianças, repensarem suas concepções e ampliarem seus conhecimentos sobre a temática.

Os alunos mostraram-se surpresos e eufóricos pela possibilidade do contato com os pequenos animais, como as minhocas, lesmas, caracóis e um exemplar de pinto, trazidos para a sala de aula. Foi interessante o quanto foi considerável para eles, tanto que foi citado por 54,90\% dos participantes. E apesar de 17,65\% afirmarem ter ficado com nojo, relataram que se sentiram desafiados a tocar os exemplares. Inclusive na fala de um aluno "Senti nojo, mas pensei, tenho que vencer meus medos e tocar. Toquei". Apenas um único aluno que afirmou ter nojo e não tocou.

Enquanto os alunos interagiam com os animais, diferentes expressões eram demonstradas, tais como admiração, estranhamento, espanto, nojo ou medo/receio de tocar. É oportuno destacar aqui os aspectos de valorização estética presente, pois as mesmas crianças que "adoravam" o pintinho, "repudiavam" os outros. Ao longo da atividade diversas perguntas foram surgindo, e os pesquisadores foram tendo a oportunidade de ir dialogando e construindo os conceitos com os estudantes. Barbosa (2015) destaca que a postura do educador ao apresentar o animal e explicar alguns tópicos antes de proceder ao toque é de extrema importância, realçando as regiões do exemplar que não devem ser tocadas. Além de orientar que não se pode ficar muito tempo manuseando o animal para que este não se estresse, enfatizando que não é um objeto e que merece ser respeitado.

Em vários momentos da SDMc, comumente foi citado os aspectos utilitaristas para alguns exemplares vivos, em especial, o uso de organismos vivos para alimentação humana e medicamentos. Os alunos inicialmente afirmaram que os seres vivos eram importantes e que seres não-vivos não, pois na fala de um aluno "pedra não serve para nada!". Inclusive usaram tal critério para agruparem as imagens (fotografias de organismos vivos) na estratégia de classificação utilizada. Quando questionados sobre estas ideias e convidados a pensarem em como os seres vivos dependem de elementos não-vivos, foi possível compreenderem que esta interdependência existe e como citado por um aluno "nossa, tudo é importante, até a pedra pode ser o esconderijo de um animal, servindo de abrigo". As visões 
da natureza que ainda permeiam o currículo escolar se mostram antropocêntricas e utilitaristas, onde os animais são apresentados segundo sua utilidade e nocividade aos seres humanos (SANTOS, 2000). Nesta perspectiva antropocêntrica, a natureza é um objeto a ser usado e consumido, com seus recursos minerais, vegetais e animais, atendendo a demanda e a voracidade do ser humano. É fundamental desenvolver na escola uma discussão ampliada a respeito. De nada adianta compreender sobre seres vivos, sem estabelecer uma relação intrínseca com a complexidade do mundo vivo e da necessidade de relações harmoniosas entre todos os elementos do ambiente. Para Lopes (2005), o diálogo com as crianças sobre estes assuntos poderá acelerar o processo de reconquista das relações harmoniosas entre os humanos e o mundo mineral, vegetal e animal. Todos os fenômenos da natureza devem ser enfocados, valorizando sua importância para a preservação do ecossistema ou para a compreensão da diversidade cultural.

Sobre esta visão utilitarista, Aragão (2006) aponta que o fato de o ser humano, estar habituado a uma vida artificial em metrópoles, afastou-o da natureza, esquecendo-a, deteriorando-a, passando a considerar-se superior. Perante isto, muitas crianças não têm contato com as plantas e chegam a não ter quase que nenhum conhecimento sobre elas. Mesmo assim, as sociedades urbanas continuam dependentes dos vegetais para a manutenção da sua qualidade de vida. Por isso, é de extrema importância que as crianças não só entendam o ciclo de vida e anatomia das plantas, como também sua importância ecológica (ASSIS; BORGHEZAN; PEREIRA, 2006).

Com isto, uma nova categoria emergiu nas respostas, demonstrando a importância com os cuidados e preservação ambiental (8,11\%). Sobre esta categoria, percebeu-se que os alunos se referiram à importância dos seres vivos, bem como, do meio ambiente, demostrando a relevância da preservação e dos cuidados ao meio em que estão inseridos. Ainda é importante destacar, que após a intervenção, 26,47\% afirmaram que seres nãovivos fornecem nutrientes e 17,65\% afirmaram que seres vivos e não-vivos necessitam um dos outros. Estes resultados revelam o mérito das atividades realizadas, uma vez que inicialmente não era reconhecida pelos alunos esta importância e apresentavam quase que exclusivamente uma visão apenas utilitarista. Pode-se a partir destes resultados, inferir a necessidade da atuação da escola no processo de conscientização ambiental, como ferramenta de conhecimento para os alunos na preservação e cuidados com o meio ambiente.

Por fim, igualmente foi representativo para os educandos o contato com exemplares vivos e alguns dos elementos apresentados, surpreendendo-os pela descoberta, emergindo a categoria reconhecimento dos exemplares como vivos e não-vivos. Quando observaram os exemplares botânicos, os estudantes, em geral afirmaram que os sais minerais, a água ou a semente eram os responsáveis pelos vegetais crescerem. O solo que antes não era citado como uma das necessidades e, além disto, foi identificado pelos pesquisadores com um obstáculo na classificação entre ser vivo e não-vivo, passou a também ser reconhecido, sanando as dúvidas iniciais. Um aluno ao início das atividades comentou que "o solo por possuir nutrientes é um ser vivo", e esta mesma constatação foi atribuída inicialmente à água. No decorrer da SDMc, os alunos discutiram sobre estes nutrientes e perceberam que apesar do solo possuir nutrientes retidos nela, esses são consumidos pelos seres vivos, tais como as plantas e os microrganismos. Isso ressalta a importância de se trabalhar na escola a relação entre os fatores bióticos e abióticos. 
Também pode ser destacado, o quanto os alunos ficaram impressionados em reconhecerem como seres vivos, outros elementos que não conheciam. Este foi o caso dos musgos, pois alguns achavam que por ser "tão bonito e macio", devia ser artificial. Para Filgueiras (2008), apesar de estudar todos os vegetais, dentro da sala de aula a variedade de espécies de plantas na natureza é pouco trabalhada, levando a uma relação de que plantas são apenas as angiospermas. Normalmente briófitas e pteridófitas são grupos ignorados. Segundo Silva e Ghilardi-Lopes (2014), a aprendizagem sobre a diversidade da vida pode ser significativa aos alunos mediante oportunidades de contato com a diversidade de espécies.

A partir da construção do experimento com o fermento, os alunos por meio da observação, refletiram e discutiram, chegando a constatação que era um ser vivo. Na fala de um aluno "o fermento está vivo". O experimento foi significativo ao ponto de 20,3\% dos alunos o citarem posteriormente nas fichas de avaliação e ainda 19,55\% explicarem como o experimento foi realizado (Quadro 1). Além disso, 46,81\% dos alunos passou a reconhecer o fermento como um ser vivo. Estes resultados são evidenciados também no Quadro 4.

Para Rui e Amado (2013), a atividade investigativa deve proporcionar condições para que os alunos possam levantar e testar suas ideias e suposições sobre os fenômenos científicos que ocorrem no seu entorno. Assim, a experimentação é fundamental para desenvolver no aluno a iniciativa pessoal e como consequência a tomada de decisão, tornando a sala de aula um espaço que possibilite ao aluno expor suas opiniões dando-Ihe liberdade para que isso ocorra. Ao criar um contexto adequado para a experimentação, os alunos refletem sobre suas concepções não-científicas e constroem juntos novas concepções, sendo essas de caráter científico.

A experiência utilizando fermento biológico buscou com que os alunos relacionassem os microrganismos encontrados no material utilizado com acontecimentos cotidianos, como, por exemplo, a importância desses microscópicos organismos na produção de alguns alimentos. Trata-se de uma consideração particularmente importante visto que, eles começam a associar os microrganismos não apenas às doenças.

Por fim, ainda foi possível identificar nos textos avaliados, mais duas categorias, que não apresentaram índices de significância: saúde (0,72\%) e erros conceituais (0,95\%). Os alunos mencionaram a importância em cuidar da saúde, se alimentar bem e lavar as mãos no recreio. Mesmo não sendo esse o foco do trabalho, discutiu-se que essas orientações podem ter vindo de casa ou até mesmo das professoras responsáveis pelas turmas. A última categoria, que evidenciou erros conceituais, ainda que não significativos, merece também ser discutida, pois sinaliza para o fato do professor dever estar atento a estes equívocos, pois a análise das produções dos alunos, com seus acertos e erros, permite ao docente a compreensão da diversidade dos esquemas dos estudantes, que são indícios sobre a concepção preponderante no processo de formulação conceitual (PINTO, 2000). Assim, o professor tem a oportunidade de discutir e reconstruir ideias baseadas na análise dos erros conceituais dos alunos, percebendo quais são suas dificuldades e possibilitando uma aprendizagem alicerçada a partir das concepções prévias de seus educandos.

Propiciar situações de aprendizagem metacognitiva oportuniza ao aluno a busca de estratégias pessoais de resolução, pois este é convidado a refletir sobre a estrutura de pensamento elaborado, argumentando, exercendo a própria capacidade de "aprender a aprender". Possibilita ainda que eles venham a questionar seus erros e que tenham um papel ativo na orientação de sua própria aprendizagem. Para Toledo, (2003) à medida que 
o ser se conscientiza das diferentes possibilidades de pensar sobre seus argumentos e se vê registrando ou falando sobre eles, estão construindo um raciocínio mais elaborado.

\section{Considerações Finais}

Os resultados e discussões apresentados permitem inferir algumas considerações sobre a importância em conhecer as concepções iniciais dos estudantes para a elaboração de estratégias didáticas. O conhecimento conceitual espontâneo adquirido pelos estudantes antes ou durante os anos iniciais é fundamental para elaboração dos conceitos científicos, e a inserção da SDMc construída, levando em consideração o conhecimento dos educandos, fez com que os estudantes se aproximassem de uma aprendizagem ativa e significativa, possibilitando a interação entre os conhecimentos prévios e os conhecimentos científicos. Com o decorrer das atividades os participantes adquiriam discernimento sobre seus pensamentos iniciais a respeito da temática e começaram a reavaliar novas hipóteses, para maior compreensão e amplitude do conteúdo. Assim, ao perceberem suas dúvidas e erros conceituais sobre o assunto, conseguiram progredir e compreender de forma significativa os fatores relacionados com o cuidado dos seres vivos, as necessidades para a sobrevivência e os cuidados a serem tomados com o meio ambiente.

Foi possível perceber a importância em utilizar diversas ferramentas didáticas, pois elas facilitam o entendimento do aluno e despertam o interesse para a temática, fundamental para se atingir os objetivos educacionais propostos. Também as atividades em grupo possibilitaram o diálogo e reflexões, oportunizando o conhecimento partilhado, tornandoos protagonistas do processo de ensino-aprendizagem.

Ao elaborar uma SDMc, as experiências vivenciadas pelos alunos na sala de aula ganharam sentido, podendo se tornar algo significativo e por consequência, contribuir para a aprendizagem se tornar eficiente, rompendo a corrente do ensino atual, favorecendo que as aulas passem de um aprendizado "memorístico" para um aprendizado efetivo. Evidenciou-se o papel das estratégias metacognitivas na potencialização da aprendizagem, por meio das quais os alunos conseguiram desenvolver maneiras eficazes para lidar com informações advindas do meio e também de seus próprios processos de pensamento, estimulando o processo de aprender a aprender.

\section{Referências}

ANDRETTA, I. et al. Metacognição e Aprendizagem: como se relacionam? Psico, Porto Alegre, PUCRS, v. 41, n. 1, p. 7-13, jan./mar. 2010.

ARAGÃO, M. J. Civilização animal: a etologia numa perspectiva evolutiva e antropológica. Pelotas: Editora da União Sul-Americana de Estudos da Biodiversidade, 2006.

ASSIS A. L. A.; BORGHEZAN, H. E PEREIRA L. T. Otimização da experiência do plantio de feijão no Ensino Fundamental. In: ENCONTRO REGIONAL SUL DE ENSINO DE BIOLOGIA, 2., 2006, Florianópolis. Anais eletrônicos... Florianópolis: UFSC, 2006. BARBOSA, T. C. D.; Educação ambiental e valores: um olhar para os animais venenosos. $86 \mathrm{f}$. Trabalho de conclusão de curso (licenciatura - Ciências Biológicas) - Universidade Estadual Paulista, Instituto de Biociências de Rio Claro, 2015. 
BARDIN, L. Análise de conteúdo. São Paulo: Edições 70, 2011.

BYRNE, J. Progression of children's ideas and understanding about microbial activity. In: CONFERENCE OF THE EUROPEAN SCIENCE EDUCATION RESEARCH ASSOCIATION, 4., 2003, Edinburgh, Scotland. Proceedings..., Esera, 2003.

BYRNE, J.; SHARP, J. Children's ideas about micro-organisms. School Science Review, v. 88, n. 322, september 2006.

CAMPANARIO e OTERO. Más allá de las ideas previas como dificultades de aprendizaje: las pautas de pensamiento, las concepciones epistemológicas y las estrategias metacognitivas de los alumnos de ciencias. Enseñanza de las Ciencias, v. 18, n. 2, p. 155-169, 2000.

CAVALCANTE, J. S.; CAVALCANTE, J. C.; LICHSTON, J. E. Percepção e Sensibilidade nos Seres Vivos. Natal: EDUFRN, RN, 2 ed. 2011.

COSTA NetO, E. M.; CARVAlHO, P. D. Percepção dos insetos pelos graduandos da Universidade Estadual de Feira de Santana, Bahia, Brasil. Acta Scientiarum, 22 (2): 423- 428, 2000 .

DUCATTI-SILVA, K. C. A formação no curso de Pedagogia para o ensino de ciências nas séries iniciais. 222 f. Dissertação de Mestrado, Programa de Pós-Graduação em Educação, Faculdade de Filosofia e Ciências, Universidade Estadual Paulista "Júlio de Mesquita Filho", Marília, SP. 2005.

FILGUEIRAS, T. S. Botânica para quem gosta de plantas. São Paulo: Livro Pronto, 2008.

FLAVELL, J. H. Developmental studies of mediated memory. In: Reese e Lipsitt (Eds.), Advances in child development and behavior (vol. 5). New York: Academic Press, 1970.

FREITAS, M. A distinção entre ser vivo e ser inanimado: uma evolução por estádios ou um problema de concepções alternativas? Revista Portuguesa de Educação, Universidade do Minho, v. 2, n. 1, p.33-51,1989.

GOLDSCHMIDT. A. I. O ensino de ciências nos anos iniciais: sinalizando possibilidades de mudanças. 225 f. Universidade Federal de Santa Maria: Santa Maria Tese (Doutorado em Educação em Ciências). 2012.

KWEN, B. H. Teachers' misconceptions of biological science concepts as revealed inscience examination papers. In: International Education Researchconference, 2005, Sydney. Proceedings...Melbourne: AARE, 2005.

LABURÚ, C. E.; ARRUDA, S. de M.; NARDI, R. Pluralismo Metodológico para o Ensino de Ciências. Ciência e Educação (UNESP), São Paulo, v.9, n.2, p. 247-260, 2003.

LAWSON, A. E. The reality of general cognitive operations. Science Education, v. 66, p. 229$241,1982$.

LOPES, M. H. As Florestas, os Rios, os Mares, Eu e os Animais. In: LOPES, M. H. (org) A Criança Descobrindo, Interpretando e Agindo sobre o Mundo. Brasília: UNESCO, Banco Mundial, Fundação Maurício Sirotsky Sobrinho, Série Fundo do Milênio para a Primeira Infância Cadernos Pedagógicos, 2005. 8 p. 
MALACARNE, D.; STRIEDER, V. M. O desvelar da ciência nos anos iniciais do Ensino Fundamental: um olhar pelo viés da experimentação. Vivências: Revista Eletrônica de Extensão da URI, v. 5, n. 7. p. 75-85, maio/2009.

MOURA, M. P. Desenvolvimento do pensamento: um estudo sobre formação de conceitos com jovens e adultos em processo de escolarização. 2000. Dissertação (mestrado) Universidade de São Paulo. São Paulo.

OLIVEIRA-FORMOSINHO, J. (2007). Pedagogia (s) da infância: reconstruindo uma práxis de participação. In J. Oliveira-Formosinho, T. Kishimioto, \& M. Pinazza, Pedagogia (s) da infância: dialogando com o passado e construindo o futuro (p. 13-36). São Paulo: Artemed.

PIAGET, J. Seis estudos de psicologia. 24 ed. Rio de Janeiro: Forense, 1976.

PINTO, N. B. O Erro como estratégia Didática. O Estudo do Erro no Ensino da Matemática Elementar. 1. ed. Campinas/SP: Papirus, 2000.

RIBEIRO, Célia. Metacognição: um apoio ao processo de aprendizagem. Psicologia: reflexão e crítica, v. 16, n. 1, p. 109-116, 2003.

ROSA, C. T. W. A metacognição e as atividades experimentais no ensino de Física. $324 \mathrm{f}$. Tese (doutorado) - Universidade Federal de Santa Catarina, Centro de Ciências da Educação. Programa de Pós-Graduação em Educação Científica e Tecnológica. Florianópolis, SC, 2011.

RUI, H. M. G.; AMADO, M. V. Ensino de Ciências: Os Fungos no nosso cotidiano - Série Guia Didático de Ciências. 1a. Edição. Vitória; Editora IFES, 2013. 72 p.

SANTOS, L. H. S. Biologia dentro e fora da escola. Edt. Mediação: Porto Alegre. 2000.

SILVA, J. N.; GHILARDI-LOPES, N. P. Botânica no Ensino Fundamental: diagnósticos de dificuldades no ensino e da percepção e representação da biodiversidade vegetal por estudantes. Revista Electrónica de Enseñanza de las Ciencias, v. 13, n. 2, p. 115-136, 2014.

TOLEDO, M. E. R. O As estratégias metacognitivas de pensamento e o registro matemático de adultos pouco escolarizados. 266 f. Tese (Doutorado), Faculdade de Educação, Universidade de São Paulo. 2003.

UNESCO. Década da Educação das Nações Unidas para um Desenvolvimento Sustentável, 2005-2014: documento final do esquema internacional de implementação, Brasília, Brasil, 2005.

VYGOTSKY, L. S. Pensamento e linguagem. 3. ed. São Paulo: Martins Fontes, 1991. 